\title{
Incarceration of the gravid uterus: a case report and literature review
}

\author{
Cha Han ${ }^{\dagger}$, Chen Wang ${ }^{\dagger}$, Lulu Han, Guoyan Liu, Huiyang Li, Fuman She, Fengxia Xue and Yingmei Wang ${ }^{*}$
}

\begin{abstract}
Background: Incarceration of the gravid uterus is a rare obstetric disorder that contributes to pregnancy-related complications. To understand its clinical characteristics and managements, we have reviewed the etiology, risk factors, clinical characteristics and current treatments of an incarcerated gravid uterus based on 162 cases reported in the English language literature, including our patient.

Case presentation: A 25-year-old primigravida, with a history of lymphatic tuberculosis, infertility due to blocked fallopian tubes and received in vitro fertilization. The patient presented with urine retention and lower abdominal pain in the early second trimester. Uterine incarceration was diagnosed based on pelvic examination and abdominal ultrasound. A Foley catheter was placed and manual reposition was successful. No episode of retention was experienced after the further enlargement of the uterus and its ascent. A healthy infant was delivered vaginally on 38th week of pregnancy.

Conclusions: Uterine incarceration due to pelvic adhesions is rare and, because of it non-specific clinical presentations, is often misdiagnosed. Abdominal ultrasound is instrumental for the diagnosis because it can directly image the disturbed uterine and pelvic anatomy. There are limited treatment options for uterine incarceration, but definitive diagnosis allows procedures to treat and to reduce severe complications of uterine incarceration.
\end{abstract}

Keywords: Retroverted uterus, Pregnancy, Incarceration, Pelvic adhesions, Complications

\section{Background}

Uterine retroversion is recognized as a normal variant and its prevalence is reported to be up to $15 \%$ of pregnancies in the first trimester [1]. In most cases, retroversion can spontaneously return to a normal axial position by 14th week of gestation when the gravid uterus grows into the abdominal cavity. In rare cases, the uterus remains retroverted and becomes retroflexed between the subpromontory sacrum and pubis in the pelvic cavity, potentially caused by uterine anomalies, fibroids, pelvic adhesions or a deep sacral cavity with a prominent promontory. Failures to timely diagnose and properly treat uterine incarceration often result in obstetric complications. Here we report a case of incarceration of a retroverted uterus with a history of in vitro fertilization and embryo

\footnotetext{
* Correspondence: yingmeiwang98@sina.com

${ }^{+}$Cha Han and Chen Wang contributed equally to this work.

Department of Gynecology and Obstetrics, Tianjin Medical University General Hospital, No. 154 Anshan Road, Heping District, Tianjin, People's Republic of China300052
}

transfer (IVF-ET). We also reviewed previous reports in the literature to highlight the importance for early recognition and prompt managements in improving outcomes for pregnant women with the condition, especially those who have difficulty becoming pregnant with assisted reproductive technology (ART).

\section{Case presentation}

A 25-year-old patient, gravida 1, para 0 , first presented to the regional hospital at 16 weeks of gestation and with chief complaints of vaginal bloody discharge for 6 days, unable to urinate, and mild lower abdominal pain. The patient was diagnosed with lymphatic tuberculosis at 17 years of age, but had no history of sexually transmitted diseases, pelvic inflammatory diseases, endometriosis, uterine leiomyomas, deep sacral concavity, surgery, or congenital uterine malformations, such as uterus didelphys. The patient experienced infertility for two years caused by bilateral obstruction of the fallopian tubes with uterine retroversion, which was detected by hystero-salpingo-graphy in the regional hospital. She

(c) The Author(s). 2019 Open Access This article is distributed under the terms of the Creative Commons Attribution 4.0 International License (http://creativecommons.org/licenses/by/4.0/), which permits unrestricted use, distribution, and 
eventually became pregnant by follicular aspiration and IVF-ET, and had been treated with daily intramuscular progesterone since the procedure. Subsequent ultrasound scans revealed normal pregnancy progression.

At 15 weeks and 2 days of gestation, small amounts of bloody vaginal discharge persisted for one day, and an ultrasound showed that the placenta covered the internal os of the cervix. She was then admitted with a diagnosis of a low position of the placenta and continued receiving progesterone therapy. She experienced worsening lower abdominal pain and difficulty with urination on fifth day after admission and was transferred to our tertiary hospital at gestational age 16 weeks and 1 day.

A repeated ultrasound scan in the tertiary hospital confirmed uterine retroversion with a fundus bending to the posterior fornix, which made the fundus into the lowest point of the uterus. The cervix was anteriorly transfixed behind the pubic symphysis and was barely above the fundus; fundal implantation of placenta was revealed (Fig. 1). A fetus with a heart rate of $156 \mathrm{bpm}$ and adequate biometric measurements for the gestational age were observed. A Foley catheter was indwelt and $1075 \mathrm{~mL}$ of urine was emptied. Afterwards, the abdomen was soft to palpation. Pelvic examination revealed that the cervix could not be reached with fingers or exposed by vaginal speculum; the uterine fundus was palpated within the curvature of the sacrum, and there were occasional palpable uterine contractions without tenderness. Attempts to reduce incarceration by intravaginal pressure in the lithotomy position, in combination with the patient's intermittent knee-chest position, were unsuccessful. However, incarceration was relieved by applying transvaginal fundal pressure in the second time. After the procedure, a 16-week-sized uterus was palpable, and the cervix was posterior in the vagina. Repeat ultrasound examinations confirmed that the uterus returned to the correct polarity. The patient could urinate without catheter. The pregnancy was subsequently uneventful, and a healthy female infant $(3570 \mathrm{~g}, 50 \mathrm{~cm}$, Apgar 9/10/10) was vaginally delivered at 38 weeks of gestation. (Case timeline see Additional file 1).

\section{Discussion and conclusions}

Incarceration of the gravid uterus refers to the entrapment of the uterus in the pelvic cavity behind the sacral promontory. It has been estimated to affect 1 in 3000 pregnancies [2]. In addition to discuss our patient, we conducted a systematic search in the PubMed database, using the following search terms sequentially applied to all English reports published until 2016 (when the search was conducted): "("retroverted uterus" OR "retroverted gravid uterus") AND ("incarceration" OR "incarcerated uterus" OR "incarcerated gravid uterus") AND ("gestation" OR "gestational" OR "pregnant" OR "pregnancy" OR "gravid uterus")". The bibliographies of relevant articles were also searched by hand to identify additional eligible studies. (Additional file 2).

We identified 162 cases including our own for analysis (Additional file 3 and Additional file 4) [3-102]. The mean age of patients was $30.49 \pm 5.66$ years $(16-42$ years of age); the gestational age at the diagnosis of incarceration ranged from 5 weeks to 42 weeks; with $15.43 \%$ (25/ $162), 51.88 \%(83 / 162)$, and $28.13 \%$ (45/162) found in the first, second, and third trimesters of pregnancy, respectively ( 9 without specific information related to the time of disease onset). Thirteen cases were diagnosed at term pregnancy. Most women became pregnant through natural conception. Eight women became pregnant with
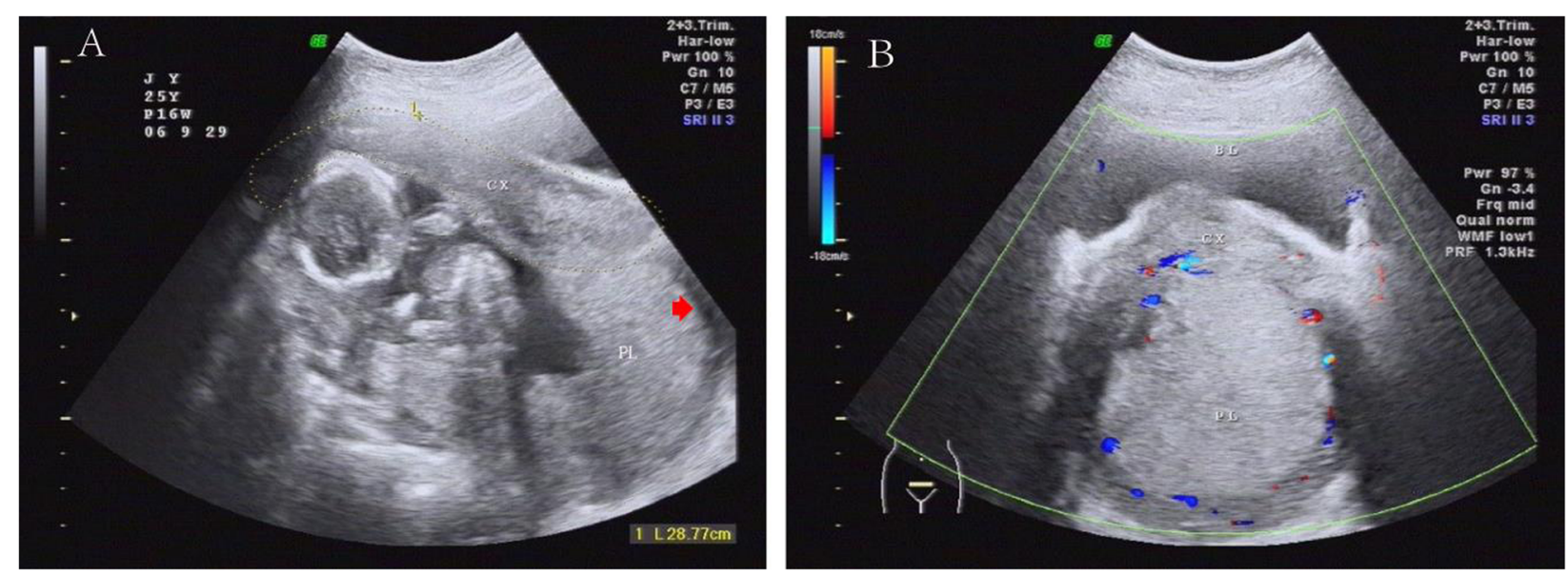

Fig. 1 Ultrasonography of the retroverted gravid incarcerated uterus in the present case. (a) A longitudinal section shows that the uterus is fixed in retroversion with the cervix anteriorly transfixed behind the pubic symphysis above the uterine fundus (red arrow indicating the uterine fundus). Placenta located at fundus of uterus. (b) A transverse image of placenta that is located below the cervix. The two positional images better defines the position of uterine retroversion. BL: bladder; CX: cervix; PL: placenta 
ART, including 6 with IVF-ET and 2 with intracytoplasmic sperm injection (ICSI).

\section{Etiology and risk factors}

The condition of a gravid uterine incarceration has no clearly identifiable causes, but is strongly correlated to malposition of the nonpregnant uterus, which is typically retroversion. In most cases, the gravid uterus transforms from a pelvic organ to an abdominal organ and the retroverted uterus corrects itself as the fundus rising out of the pelvis between 12 and 14 weeks of gestation and spontaneously falling forward to its normal anatomical position. On rare occasions, the uterus remains in a retroverted position and is trapped in the pelvic cavity. Multiple factors have been identified to prevent the uterus from entering the abdominal cavity, including tumor, uterine malformation, pelvic adhesions secondary to abdominal surgery, inflammation in the pelvis, and endometriosis. Among the 136 patients reviewed, 3 patients had uterine anomalies (didelphic uterus $2[18,69]$ and bicornuate uterus 1 [59]); 1 had abdominal surgery and presented with serious pelvic adhesion [52]; 1 had a deep sacral concavity [77]; and 1 had a history of cystitis [27]. Two patients reported no special history [62, 80] and the risk information was not available for 2 patients [33, 82]. Uterine prolapse, deep sacral concavity, and uterine fibroids are also identified as significant risk factors for a gravid uterus to develop incarceration $[68,77,80]$. It is noteworthy that there were 10 cases of recurrent incarceration $[18,27,33,52,59,62,69,77,80,82]$. It appears that pregnant women who had experienced incarceration, especially those with known risk factors discussed above are likely to develop recurrent incarceration during the subsequent gestation.

Eight patients became pregnant through ART [63, $64,66,77,82,93]$ and carried significant risk factors for incarceration. There is no definitive report that associates incarceration in pregnant women with ART, but common risk factors associated with incarceration, such as endometriosis or pelvic inflammatory diseases, have also been identified for infertility. Gravid uterine incarceration should therefore be considered if a pregnant woman through ART develops abdominal pain and vaginal bleeding. Since woman with ART often receive more extensive monitoring during their pregnancies, gravid uterine incarceration may be diagnosed early and a timely manner, leading to fewer complications. In fact, 7 patients in sporadic case reports who successfully delivered infants because of prompt diagnosis through pelvic examination and abdominal imaging. Our patient had a history of lymphatic tuberculosis that could result in pelvic adhesion and bilateral tubal blockage, both of which could contribute to the development of uterine incarceration.

\section{Symptoms and diagnosis}

Among the 162 reviewed cases, gravid uterine incarceration is mostly diagnosed in the second trimester. The symptoms of gravid uterine incarceration vary, but include urinary manifestations $(53.70 \%$, urinary retention, frequent urination, dysuria, urgency and paradoxical incontinence), abdominal pain (35.80\%), constipation (6.79\%), vaginal bleeding (6.17\%), pelvic pain $(6.79 \%)$, back pain $(4.94 \%)$, tenesmus $(1.85 \%)$, perineal pain $(0.62 \%)$, and large painful mass prolapsed outside the anus $(0.62 \%)$. Fourteen patients (8.64\%) are asymptomatic, but also have delivered viable infants in the end, indicating that asymptomatic patients may better outcomes of pregnancy compared to those with severely symptomatic. Clinical complications usually occur after twelve weeks of gestation and are mostly related to the pressure from anatomical structures adjacent to the entrapped uterus, including lower abdominal and pelvic pain, dysuria, urinary frequency, urinary retention, overflow incontinence, rectal pressure, and worsening constipation $[66,92]$. Among these, urinary retention is the most common symptom that occurs because of elongation of the urethra by displacement of the cervix, loss of the urethrovesical angle, and mechanical compression of the bladder neck. If an incarcerated uterus is not diagnosed and treated promptly, we speculate that bladder rupture, renal failure, spontaneous abortion, intra-uterine growth retardation, prematurity and premature rupture of the membranes, or even uterine sacculation or rupture may happen frequently.

Diagnosis of uterine incarceration remains difficult because its symptoms are often non-specific and absent in early pregnancy [82]. It is worth noting that in case reports, all diagnoses were made by clinical suspicion alone before 1969, but after 1974, especially after 2000, an increasing number of cases benefited from pelvic examination combined with imaging methods based on suspected symptoms. This could be explained by advances in imaging technology in recent years, which also indicated that ultrasound scanning or MRI facilitated early recognition and appropriate treatment of uterine incarceration.

In general, the features of pelvic examination can be described as follows. The cervix is anteriorly transfixed behind the pubic symphysis, making it difficult to expose. Additionally, sacculation of the posterior wall of the vagina and posterior fornix bulge may be observed, and the fundus is palpable within the curvature of the sacrum and could not be moved. 
Ultrasound examination could confirm incarceration. Abdominal sonography shows an advantage over transvaginal sonography in exhibiting the position of the cervix and its internal ostium and in determining the relationships between vagina, uterus and bladder, when the cervix is elongated and wedged behind the symphysis [80]. MRI is superior to ultrasound in the detailed scanning of gravid uterus incarceration [103]. It is suggested that every pregnant woman with an incarceration of the uterus should have MRI [104]. However, if the diagnosis is not suspected, the imaging findings can be misinterpreted as an intraperitoneal pregnancy, placenta previa or incorrect fetal presentation [88]. For our case, bloody vaginal discharge occurred at 15 weeks and 2 days of gestation, and urinary retention followed in the 16th week gestation. Even worse, this patient was misdiagnosed with a low position of the placenta based on an incorrect interpretation of the ultrasound scan in a local hospital.

\section{Treatment}

No single treatment can be deemed more successful than the others for gravid uterus incarceration. Most obstetricians tend to replace the uterus in its natural position as soon as possible after diagnosis [80]. According to the gestational age, various management options may be considered. When incarceration of the retroverted gravid uterus is diagnosed in the late early trimester or early second trimester, obstetricians should fully evaluate the possibility of turning the uterus to a normal position. A passive reduction from a repeated knee-chest position after emptying the bladder can be recommended before 14 weeks of gestation. Between 14 and 20 weeks, the patient can also attempt a knee-chest position. If this method is unsuccessful, manual manipulation can be attempted. It is recommended to do this maneuver before 20 weeks of gestation, for more complications such as preterm labor may be caused by manual manipulation later than 20th week of gestation [105]. All maneuvers should only be performed after the bladder and bowel have been emptied, to reduce the risk of rupture of the bladder, bowel or uterus [48]. Additionally, pessary may be helpful after repositioning $[1,10,19,90]$. Colonoscopic insufflation of the rectosigmoid at a gestational age of 13-15 weeks helped the reposition of the incarcerated uterus, which was reported by Seubert et al. [55]. It has been reported that the epidural anesthesia is an effective way to manage reduction of an incarcerated uterus [54]. In our literature review, six cases ended in a normal pregnancy after reposition under anesthesia [1, 27, 43, 83, 91, 92]. Anesthesia may increase the chance of a successful reduction because the uterus was easily released under anesthesia. If all interventions fail, laparoscopy or laparotomy is usually performed [66]. Operative procedures are not appropriate for patients with uterine incarceration, which is diagnosed before 20 weeks of gestation, because they can result in abortion or preterm delivery; furthermore, following such procedures, close follow-up is needed during the remainder of pregnancy. In the third trimester, uterine contractions usually fail to dilate the cervix because of incarceration. As a result, the risk of uterine rupture should be considered [85]. Caesarean section should be planned if reduction cannot be performed during the remainder of pregnancy $[70,78]$.

In 162 reviewed cases, cases of incarceration recognized in the first or second trimester of pregnancy account for $67.28 \%$ (109/162). Treatment of reposition was successfully attempted in 83 cases. After reposition, 68 patients successfully delivered infants $[2,15,16,19,21$, $23,25,27,28,36,37,41,43,44,48,50,55,62,63,66$, $76,77,82,83,85,88-92,95,98-101]$, including 36 term deliveries $[16,19,21,27,28,35,37,41,43,44,48,50$, $62,66,76,77,87,91,98,100,101]$, and information for other cases was not available. Treatment methods vary in invasiveness, and because incarceration was quite rare, no study has yet been performed to determine the supremacy of any single treatment modality.

In the present case, the patient achieved correction from incarceration, which was presumed to be related to pelvic adhesions at 16 weeks, by manual manipulation, allowing for an attempt at repositioning. However, it could not be neglected that this patient had a past medical history that involved a high correlation with pelvic adhesions, which could prevent the gravid uterus from normal enlargement and ascent due to possible refractory incarceration. If this patient did not experience relief from incarceration via manual reposition, surgery with laparotomy or laparoscopy might be considered based on the patient's strong desire to deliver a healthy child.

In conclusion, we report a case of gravid uterine incarceration with a history of lymphatic tuberculosis and IVF-ET. The particular risk factors, including a past history of infection and pregnancy by ART, made our case a relatively specific. As illustrated in the review of similar case reports, gravid uterine incarceration is a rare condition, but serious late gestational complications or poor obstetric outcomes may occur. Early diagnosis is the key to successful treatment. In view of the lack of specific signs or symptoms, additional physical and imaging examinations are critical to early diagnosis of this condition. Appropriate treatment measures that are tailored to the different gestation weeks may improve pregnancy outcomes. 


\section{Supplementary information}

Supplementary information accompanies this paper at https://doi.org/10. 1186/s12884-019-2549-3.

Additional file 1. Case timeline. Describe the past medical history and interventions, summaries from initial and follow-up visits, diagnostic testing, interventions and relevant dates. (DOCX $17 \mathrm{~kb}$ )

Additional file 2. PRISMA flow diagram. Search terms sequentially applied to all English reports published until 2016 (when the search was conducted): "(retroverted uterus" OR "retroverted gravid uterus") AND ("incarceration" OR "incarcerated uterus" OR "incarcerated gravid uterus") AND ("gestation" OR "gestational" OR "pregnant" OR "pregnancy" OR "gravid uterus")". The bibliographies of relevant articles were also searched by hand to identify additional eligible studies. (DOC $33 \mathrm{~kb}$ )

Additional file 3. Case reports of incarceration of the retroverted uterus that have been reported in the literature (chronologically, up to 2016). There were 162 cases published, including the present case, based on all available articles which could be searched for in the PubMed database. Basic information of the patients and associated information from each case report worldwide were summarized for readers to obtain a general view on this condition, including possible risk factors, symptoms, diagnosis, treatment and outcomes. (DOCX $76 \mathrm{~kb}$ )

Additional file 4. Maternal characteristics with incarceration of the gravid uterus. Based on the 162 case reports, we conducted statistical analysis and summarized the maternal characteristics in the table. (DOCX $19 \mathrm{~kb})$

\section{Abbreviations}

ART: Assisted reproductive technology; BL: Bladder; CS: Caesarean section; CT: Computed tomography; CX: Cervix; G: Gravid; GA: Gestational age (weeks); ICSI: Intracytoplasmic sperm injection; IVF-ET: In vitro fertilization and embryo transfer; LEEP: Loop electrosurgical excision procedure MRI: Magnetic resonance imaging; NA: Not available; P: Partus; PL: Placenta; US: Ultrasound scan

\section{Acknowledgements}

Not applicable.

\section{Authors' contributions}

$\mathrm{CH}$ and $\mathrm{CW}$ contributed equally in writing the manuscript. $\mathrm{CW}, \mathrm{CH}, \mathrm{LH}, \mathrm{GL}$ and $\mathrm{HL}$ collected the data of the cases. CW, HL, FS helped to search relevant articles for analysis. FX and YW reviewed the manuscript. All authors read and approved the final manuscript.

\section{Authors' information}

All authors were from Department of Gynecology and Obstetrics, Tianjin Medical University General Hospital, Tianjin, China.

\section{Funding}

This study was supported by the Tianjin Municipal Natural Science

Foundation (No. 16JCYBJC26400) in the collection, interpretation of data and publication.

\section{Availability of data and materials}

All data generated or analysed during this study are included in this article.

\section{Ethics approval and consent to participate}

Not applicable.

\section{Consent for publication}

The patient whose story is told in this case report has provided written consent for all figures to be published, and for the publication of potentially identifying information.

\section{Competing interests}

The authors declare that they have no competing interests.
Received: 7 September 2018 Accepted: 4 October 2019

Published online: 08 November 2019

\section{References}

1. Sweigart AN, Matteucci MJ. Fever, sacral pain, and pregnancy: an incarcerated uterus. West J Emerg Med. 2008;9:232-4.

2. Hamod H, Chamberlain PF, Moore NR, Mackenzie IZ. Conservative treatment of an incarcerated gravid uterus. BJOG. 2002;109:1074-5.

3. Oldham $\mathrm{H}$. Case of retroflexion of the gravid uterus during labour at term. Trans Obstet Soc Lond. 1895;1:317-22.

4. Maiss. Retroflexio uteri gravidi partialis: spontanruptur bei der Geburt. Arch Gynaekol 1899; 58:125-133.

5. Stevens TG. Case of Sacculation of a Gravid Bicornute Uterus. Proc R Soc Med 1920; 13(Obstet Gynaecol Sect):154-156.

6. Dorman FA. Posterior sacculation of bicornate uterus-cesarian section. Am J Obstet Gynecol. 1923;6:218-9.

7. Oldfield C. Unusual case of obstructed labour, due to retroflexion of the fulltime gravid uterus. Trans North Engl Obstet Gynaecol Soc. 1931-1932:29.

8. Murray F. Caesarean section on an incarcerated retroverted gravid uterus at term. J Obstet Gynaecol Br Emp. 1934:41:840.

9. Mendoza JT. Incarceration of 6 month gravid uterus; report of a case. Philipp J Surg. 1948:3:60-3.

10. Burdon S, Maurer JE, Lich R Jr. Acute retention in pregnancy. J Urol. 1951;65: 578-80

11. Seidner HM, Arnkoff M, Mills GY. Urinary retention in pregnancy. J Am Med Assoc. 1952;149:425-6.

12. Spring $M$, Hymes JJ. Acute urinary retention as a complication of pregnancy; report of a case. J Am Med Assoc. 1952;149:1011-2.

13. Freeth $D$, Dring AP. Incarceration and sacculation of the uterus with rupture of the cervix. Br Med J. 1953;1:202.

14. Ney C, Hyman RM. Complete urinary retention in female. Am J Surg. 1954; 87:34-40.

15. Devoe RW. Acute urinary retention in pregnancy; report of a case. Calif Med. 1956;85:112-3.

16. Terry RB. Incarcerated retroflexed gravid uterus; simple maneuver for its correction. Obstet Gynecol. 1959;13:630-1.

17. Smith JJ, Schwartz ED, Romney SL. Anterior sacculation of the pregnant uterus. Obstet Gynecol. 1962;20:536-8.

18. Wood PA. Posterior sacculation of the uterus in a patient with a double uterus. Am J Obstet Gynecol. 1967;99:907-8.

19. Gibbons JM Jr, Paley WB. The incarcerated gravid uterus. Obstet Gynecol. 1969:33:842-5.

20. Fadel HE, Misenhimer HR. Incarceration of the retroverted gravid uterus with sacculation. Obstet Gynecol. 1974:43:46-9.

21. Swartz EM, Komins Jl. Postobstructive diuresis after reduction of an incarcerated gravid uterus. J Reprod Med. 1977;19:262-4.

22. Spearing GJ. Uterine sacculation. Obstet Gynecol (Suppll) 1978;51:11s-13s.

23. Laing FC. Sonography of a persistently retroverted gravid uterus. AJR Am J Roentgenol. 1981;136:413-4.

24. Kondo A, Otani T, Takita T, Hayashi H, Kihira M, Itoh F. Urinary retention caused by impaction of enlarged uterus. Urol Int. 1982;37:87-90.

25. Chatterjee G, Biswas BP, Biswas S. Sacculation of pregnant uterus. J Indian Med Assoc. 1984:82:365-8.

26. Nelson MS. Acute urinary retention secondary to an incarcerated gravid uterus. Am J Emerg Med. 1986:4:231-2.

27. Silva PD, Berberich W. Retroverted impacted gravid uterus with acute urinary retention: report of two cases and a review of the literature. Obstet Gynecol. 1986;68:121-3.

28. Evans AJ, Anthony J, Masson GM. Incarceration of the retroverted gravid uterus at term. Case report Br J Obstet Gynaecol. 1986;93:883-5.

29. Schwartz Z, Dgani R, Katz Z, Lancet M. Urinary retention caused by impaction of leiomyoma in pregnancy. Acta Obstet Gynecol Scand. 1986;65: 525-6.

30. Edminster SC, Raabe RD, Kates RB. The incarcerated gravid uterus. Ann Emerg Med. 1987;16:910-2.

31. Meislin HW. Incarceration of the gravid uterus. Ann Emerg Med. 1987;16: 1177-8

32. Vleugels MP, Meuwissen JH. Confusing presentation in a retroflexed septate uterus at term. Eur J Obstet Gynecol Reprod Biol. 1987;24:237-41.

33. McGann KP, Griffin WT. Recurrent classical sacculation of the pregnant uterus. J Fam Pract. 1988;26:339-41. 
34. Jackson D, Elliott JP, Pearson M. Asymptomatic uterine retroversion at 36 weeks' gestation. Obstet Gynecol. 1988;71:466-8.

35. Hess LW, Nolan TE, Martin RW, Martin JN Jr, Wiser WL, Morrison JC. Incarceration of the retroverted gravid uterus: report of four patients managed with uterine reduction. South Med J. 1989;82:310-2.

36. Hankins GD, Cedars MI. Uterine incarceration associated with uterine leiomyomata: clinical and sonographic presentation. J Clin Ultrasound. 1989; 17:385-8.

37. Smalbraak I, Bleker OP, Schutte MF, Treffers PE. Incarceration of the retroverted gravid uterus: a report of four cases. Eur J Obstet Gynecol Reprod Biol. 1991;39:151-5.

38. Van Winter JT, Ogburn PL Jr, Ney JA, Hetzel DJ. Uterine incarceration during the third trimester: a rare complication of pregnancy. Mayo Clin Proc. 1991; 66:608-13

39. Keating PJ, Walton SM, Maouris P. Incarceration of a bicornuate retroverted gravid uterus presenting with bilateral ureteric obstruction. Br J Obstet Gynaecol. 1992;99:345-7.

40. Gunn AP. Incarcerated gravid uterus mimicking placenta praevia. Australas Radiol. 1993:37:93-4.

41. Hill LM, Chenevey P, DiNofrio D. Sonographic documentation of uterine retroversion mimicking uterine sacculation. Am J Perinatol. 1993;10:398-400.

42. Nwosu UC, Thatcher S. Pregnancy in a non-communicating uterine horn mimicking incarceration with sacculation of a retroflexed uterus. Acta Obstet Gynecol Scand. 1993;72:580-2.

43. Lettieri L, Rodis JF, McLean DA, Campbell WA, Vintzileos AM. Incarceration of the gravid uterus. Obstet Gynecol Surv. 1994;49:642-6.

44. Wittich AC, Polzin WJ, Thomas CS. Incarceration of the gravid uterus due to an impacted leiomyoma: a case report. Mil Med. 1994;159:583-4.

45. Emery D, Nolan R. Ultrasonography of an incarcerated uterus during pregnancy. Can Assoc Radiol J. 1994:45:397-8.

46. Myers DL, Scotti RJ. Acute urinary retention and the incarcerated, retroverted, gravid uterus. A case report. J Reprod Med. 1995;40(6):487-90.

47. Renaud MC, Bazin S, Blanchet P. Asymptomatic uterine incarceration at term. Obstet Gynecol. 1996;88:721.

48. Patterson E, Herd AM. Incarceration of the uterus in pregnancy. Am J Emerg Med. 1997:15:49-51.

49. Feusner AH, Mueller PD. Incarceration of a gravid fibroid uterus. Ann Emerg Med. 1997:30:821-4.

50. Hirsch E. Anterior uterine incarceration. Int J Gynaecol Obstet. 1997;57:195-7.

51. Dietz HP, Teare AJ, Wilson PD. Sacculation and retroversion of the gravid uterus in the third trimester. Aust N Z J Obstet Gynaecol. 1998; 38:343-5.

52. Jacobsson B, Wide-Swensson D. Recurrent incarceration of the retroverted gravid uterus-a case report. Acta Obstet Gynecol Scand. 1999;78:737.

53. O'Connell MP, Ivory CM, Hunter RW. Incarcerated retroverted uterus--a non recurring complication of pregnancy. J Obstet Gynaecol. 1999;19:84-5.

54. Algra $\sqcup$, Fogel ST, Norris MC. Anesthesia for reduction of uterine incarceration: report of two cases. Int J Obstet Anesth. 1999:8:142-3.

55. Seubert DE, Puder KS, Goldmeier P, Gonik B. Colonoscopic release of the incarcerated gravid uterus. Obstet Gynecol. 1999;94:792-4.

56. Love JN, Howell JM. Urinary retention resulting from incarceration of a retroverted, gravid uterus. J Emerg Med. 2000;19:351-4.

57. DeFriend DE, Dubbins PA, Hughes PM. Sacculation of the uterus and placenta accreta: MRI appearances. Br J Radiol. 2000;73:1323-5.

58. Li YT, Tsui MS, Yin CS, Lin HM, Chan CC. Asymptomatic uterine incarceration at term gestation: a case report. J Obstet Gynaecol Res. 2000;26:31-3.

59. Minassian VA, Dunn M. Recurrent sacculation of the pregnant uterus. A case report. J Reprod Med. 2000;45:1003-6.

60. Yohannes $P$, Schaefer J. Urinary retention during the second trimester of pregnancy: a rare cause. Urology. 2002;59:946

61. Uma R, Oláh KS. Transvaginal caesarean hysterectomy: an unusual complication of a fibroid gravid uterus. BJOG. 2002;109:1192-4.

62. van Beekhuizen HJ, Bodewes HW, Tepe EM, Oosterbaan HP, Kruitwagen R Nijland R. Role of magnetic resonance imaging in the diagnosis of incarceration of the gravid uterus. Obstet Gynecol. 2003;102:1134-7.

63. Childs AJ, Goldkrand JW. Uterine incarceration in a 9-week multifetal pregnancy resulting from in vitro fertilization. A case report. J Reprod Med. 2003:48:992-4.

64. Matsushita H, Kurabayashi T, Higashino M, Kojima Y, Takakuwa K, Tanaka K. Incarceration of the retroverted uterus at term gestation. Am J Perinatol. 2004:21:387-9.
65. Yang JM, Huang WC. Sonographic findings in acute urinary retention secondary to retroverted gravid uterus: pathophysiology and preventive measures. Ultrasound Obstet Gynecol. 2004;23:490-5.

66. Inaba F, Kawatu T, Masaoka K, Fukasawa I, Watanabe H, Inaba N. Incarceration of the retroverted gravid uterus: the key to successful treatment. Arch Gynecol Obstet. 2005:273:55-7.

67. Frei KA, Duwe DG, Bonel HM, Dürig P, Schneider H. Posterior sacculation of the uterus in a patient presenting with flank pain at 29 weeks of gestation. Obstet Gynecol. 2005;105:639-41.

68. Ozel B. Incarceration of a retroflexed, gravid uterus from severe uterine prolapse: a case report. J Reprod Med. 2005;50:624-6.

69. Sutter R, Frauenfelder T, Marincek B, Zimmermann R. Recurrent posterior sacculation of the pregnant uterus and placenta increta. Clin Radiol. 2006; 61:527-30.

70. Singh MN, Payappagoudar J, Lo J, Prashar S. Incarcerated retroverted uterus in the third trimester complicated by postpartum pulmonary embolism. Obstet Gynecol. 2007:109:498-501.

71. Barton-Smith P, Kent A. Asymptomatic incarcerated retroverted uterus with anterior sacculation at term. Int J Gynaecol Obstet. 2007:96:128.

72. Chauleur $C$, Vulliez $L$, Seffert $P$. Acute urine retention in early pregnancy resulting from fibroid incarceration: proposition for management. Fertil Steril. 2008;90:1198.e7-10.

73. Charova J, Yunus D, Sarkar PK. Incarcerated retroverted gravid uterus presenting as placenta praevia. J Obstet Gynaecol. 2008;28:537-9.

74. Gottschalk EM, Siedentopf JP, Schoenborn I, Gartenschlaeger S, Dudenhausen JW, Henrich W. Prenatal sonographic and MRI findings in a pregnancy complicated by uterine sacculation: case report and review of the literature. Ultrasound Obstet Gynecol. 2008;32:582-6.

75. Lee SW, Kim MY, Yang JH, Moon MH, Cho JY. Sonographic findings of uterine sacculation during pregnancy. Ultrasound Obstet Gynecol. 2008;32: 595-7.

76. Rose $\mathrm{CH}$, Brost BC, Watson WJ, Davies NP, Knudsen JM. Expectant management of uterine incarceration from an anterior uterine myoma: a case report. J Reprod Med. 2008;53:65-6.

77. Hooker AB, Bolte AC, Exalto N, Van Geijn HP. Recurrent incarceration of the gravid uterus. J Matern Fetal Neonatal Med. 2009;22:462-4.

78. van der Tuuk K, Krenning RA, Krenning G, Monincx WM. Recurrent incarceration of the retroverted gravid uterus at term-two times transvaginal caesarean section: a case report. J Med Case Rep. 2009;3:103.

79. Gerscovich EO, Maslen L. The retroverted incarcerated uterus in pregnancy: imagers beware. J Ultrasound Med. 2009;28:1425-7.

80. Dierickx I, Mesens T, Van Holsbeke C, Meylaerts L, Voets W, Gyselaers W. Recurrent incarceration and/or sacculation of the gravid uterus: a review. J Matern Fetal Neonatal Med. 2010;23:776-80.

81. Al Wadi K, Helewa M, Sabeski L. Asymptomatic uterine incarceration at term: a rare complication of pregnancy. J Obstet Gynaecol Can. 2011;33:729-32.

82. Dierickx I, Van Holsbeke C, Mesens T, Gevers A, Meylaerts L, Voets W, et al. Colonoscopy-assisted reposition of the incarcerated uterus in midpregnancy: a report of four cases and a literature review. Eur J Obstet Gynecol Reprod Biol. 2011;158:153-8.

83. Grossenburg NJ, Delaney AA, Berg TG. Treatment of a late second-trimester incarcerated uterus using ultrasound-guided manual reduction. Obstet Gynecol. 2011;118:436-9.

84. Al Wadi K, Helewa M, Sabeski L. Asymptomatic uterine incarceration at term: a rare complication of pregnancy. J Obstet Gynaecol Can. 2011; 33:729-32.

85. Wang L, Wang J, Huang L. Incarceration of the retroverted uterus in the early second trimester performed by hysterotomy delivery. Arch Gynecol Obstet. 2012;286:267-9.

86. Hachisuga N, Hidaka N, Fujita Y, Fukushima K, Wake N. Significance of pelvic magnetic resonance imaging in preoperative diagnosis of incarcerated retroverted gravid uterus with a large anterior leiomyoma: a case report. J Reprod Med. 2012;57:77-80.

87. Shima E, Serikawa T, Itsukaichi M, Haino K, Ooki I, Takakuwa K, et al. Pregnancy complicated by uterine sacculation due to a huge myoma. J Obstet Gynaecol Res. 2012;38:1111-4.

88. Fernandes DD, Sadow CA, Economy KE, Benson CB. Sonographic and magnetic resonance imaging findings in uterine incarceration. J Ultrasound Med. 2012;31:645-50.

89. Katopodis C, Menticoglou S, Logan A. Incarcerated fibroid uterus: the role of conservative management. J Obstet Gynaecol Can. 2013;35:536-8. 
90. Dierickx I, Delens F, Backaert T, Pauwels W, Gyselaers W. Case report: incarceration of the gravid uterus: a radiologic and obstetric challenge. Radiol Case Rep. 2014;8:28-36.

91. Policiano C, Araújo C, Santo S, Centeno M, Pinto L. Incarcerated gravid uterus: early manual reduction vs. late spontaneous resolution. Eur J Obstet Gynecol Reprod Biol. 2014;180:201-2.

92. Newell SD, Crofts JF, Grant SR. The incarcerated gravid uterus: complications and lessons learned. Obstet Gynecol. 2014;123:423-7.

93. Matsushita H, Watanabe K, Wakatsuki A. Management of a second trimester miscarriage in a woman with an incarcerated retroverted uterus. J Obstet Gynaecol. 2014;34:272-3.

94. Slama R, Barry M, McManus K, Latham D, Berniard M. Uterine incarceration: rare cause of urinary retention in healthy pregnant patients. West J Emerg Med. 2015;16:790-2.

95. Díaz EG, Olivas PO, Fernández CF, González NG, Corona AF. Acute urinary retention due to an incarcerated Retroverted gravid uterus. J Health Med Informat. 2015;6:193.

96. Ozyurek ES, Kahraman AA, Yildirim D, Karacaoglu UM. Clinical presentation of placenta percreta with uterine incarceration in the second trimester. J Obstet Gynaecol. 2015;35(6):641-3.

97. Hassanin IH, Helmy YA, Abbas AM, Shaaban OM, Khalaf M, Ahmed SR, et al. Incarcerated gravid uterus through a rectal prolapse: first case report. Eur Obstet Gynecol Reprod Biol. 2016;204:127-8

98. Sadath $\mathrm{H}$, Carpenter R, Adam K. Uterine incarceration in a primigravid retroverted bicornuate uterus. BMJ Case Rep. 2016. https://doi.org/10.1136/ bcr-2016-215245.

99. Takami M, Hasegawa Y, Seki K, Hirahara F, Aoki S. Spontaneous reduction of an incarcerated gravid uterus in the third trimester. Clin Case Rep. 2016;4: 605-10.

100. Kim SC, Lee YJ, Jeong JE, Joo JK, Lee KS. Incarceration of gravid uterus by growing subserosal myoma: case report. Clin Exp Obstet Gynecol. 2016;43: $131-3$.

101. Pabuçcu EG, Kiseli M, Yarci Gursoy A, Bostanci A, Caglar GS, Dincer CS Successful vaginal delivery at term following ventro-fixation procedure for uterine incarceration. J Obstet Gynaecol. 2016;36(7):869-72.

102. Schwope RB, Ritter JL, Lisanti CJ, Reiter MJ. Uterine incarceration: imaging findings on magnetic resonance imaging. J Emerg Med. 2016;51(3):e49-50

103. Gardner CS, Jaffe TA, Hertzberg BS, Javan R, Ho LM. The incarcerated uterus: a review of MRI and ultrasound imaging appearances. AJR Am J Roentgenol. 2013;201:223-9.

104. Dierickx I, Meylaerts LJ, Van Holsbeke CD, et al. Incarceration of the gravid uterus: diagnosis and preoperative evaluation by magnetic resonance imaging. Eur J Obstet Gynecol Reprod Biol. 2014;179:191-7.

105. Jacobsson B, Wide-Swensson D. Incarceration of the retroverted gravid uterus: a review. Acta Obstet Gynecol Scand. 1999;78:665-8.

\section{Publisher's Note}

Springer Nature remains neutral with regard to jurisdictional claims in published maps and institutional affiliations.

Ready to submit your research? Choose BMC and benefit from:

- fast, convenient online submission

- thorough peer review by experienced researchers in your field

- rapid publication on acceptance

- support for research data, including large and complex data types

- gold Open Access which fosters wider collaboration and increased citations

- maximum visibility for your research: over $100 \mathrm{M}$ website views per year

At $\mathrm{BMC}$, research is always in progress.

Learn more biomedcentral.com/submissions 